\title{
Reducing Energy Requirements in the Production of Acrylic Acid: Simulation and Design of a Multitubular Reactor Train
}

\author{
Kiara Capreece Premlall and David Lokhat*
}

School of Engineering, University of KwaZulu-Natal, Durban 4051, South Africa; lovekiara@hotmail.co.za

* Correspondence: lokhat@ukzn.ac.za; Tel.: +27-031-2601-897

Received: 26 February 2020; Accepted: 27 March 2020; Published: 16 April 2020

\begin{abstract}
Acrylic acid, a versatile chemical intermediate, is typically manufactured via a two-step process involving the selective oxidation of propylene and acrolein. This work presents an optimized simulation on Aspen Plus ${ }^{\circledR}$ (AspenTech, Bedford, MA, USA) of the production of acrylic acid, with focus on the optimum design and operation of the reactor train, and modification for reduction in energy usage. In the propylene oxidation reactor, an inert pre-heating zone was designed to make use of the excess energy present in the exothermic process fluid and carried within the molten salt cooling fluid circuit. In the acrolein oxidation reactor, injection of cold air was used as a means to absorb the reaction heat. The optimization methodology employed aimed to minimize the total capital expenditure (i.e., equipment sizing) and operating costs (heat exchange network) for the required acrylic acid production and design constraints. The design constraints were based on the selected reaction kinetics and design heuristics for an optimum reactor design in this service from literature. Sensitivity analyses conducted on Aspen Plus ${ }^{\circledR}$ (AspenTech, Bedford, MA, USA) were used to determine both the interactions between and grouping of the critical parameters for the optimization. Elimination of the conventional fired preheater from the propylene oxidation reactor resulted in energy savings of almost $7 \mathrm{MW}$, with the reduction in cooling fluid pumping power for the acrolein oxidation reactor amounting to $5 \mathrm{~kW}$.
\end{abstract}

Keywords: acrylic acid; propylene oxidation; multitubular reactor; optimization

\section{Introduction}

Acrylic acid is a widely used chemical intermediate in the polymer and textile industry. There are numerous technologies available for the production of both ester and glacial acrylic acid, however the most popular route is via the partial oxidation of propylene. Propylene is contacted with steam and air in a two-step reactor train, which uses different catalysts. In the first reactor, propylene is oxidized to acrolein followed by acrolein oxidation to acrylic acid in the second reactor [1]. The main partial oxidation reactions occurring in each reactor are indicated by Equations (1) and (2). Several side reactions can also occur, with the main byproducts being acetic acid and carbon dioxide [2].

$$
\begin{array}{cc}
\mathrm{C}_{3} \mathrm{H}_{6}+\mathrm{O}_{2} \rightarrow \mathrm{C}_{3} \mathrm{H}_{4} \mathrm{O}+\mathrm{H}_{2} \mathrm{O} & \text { Acrolein } \\
\mathrm{C}_{3} \mathrm{H}_{4} \mathrm{O}+\frac{1}{2} \mathrm{O}_{2} \rightarrow \mathrm{C}_{3} \mathrm{H}_{4} \mathrm{O}_{2} & \text { Acrylic Acid } \\
\mathrm{C}_{3} \mathrm{H}_{6}+\frac{9}{2} \mathrm{O}_{2} \rightarrow 3 \mathrm{CO}_{2}+3 \mathrm{H}_{2} \mathrm{O} & \text { Carbon Dioxide } \\
\mathrm{C}_{3} \mathrm{H}_{6}+\frac{3}{2} \mathrm{O}_{2} \rightarrow \mathrm{C}_{3} \mathrm{H}_{4} \mathrm{O}_{2}+\mathrm{H}_{2} \mathrm{O} & \text { Acrylic Acid } \\
\mathrm{C}_{3} \mathrm{H}_{4} \mathrm{O}+\frac{3}{2} \mathrm{O}_{2} \rightarrow \mathrm{C}_{2} \mathrm{H}_{4} \mathrm{O}_{2}+\mathrm{CO}_{2} & \text { Acetic Acid }
\end{array}
$$




$$
\mathrm{C}_{3} \mathrm{H}_{4} \mathrm{O}+\frac{7}{2} \mathrm{O}_{2} \rightarrow 3 \mathrm{CO}_{2}+2 \mathrm{H}_{2} \mathrm{O} \quad \text { Carbon Dioxide }
$$

Presently, acrylic acid production occurs in multitubular reactors consisting of up to 30,000 tubes with small diameters to ensure that thermal radial gradients are reduced whilst increasing the available heat exchange area for optimal and rapid heat removal by a circulating heat transfer fluid on the shell side [3]. Propylene and acrolein partial oxidation reactions are highly exothermic and therefore susceptible to thermal runaway, catalyst degradation and the promotion of unwanted side reactions. As such, effective heat removal is essential to maintain the required production rates and avoid irregular hotspots within the reactor. Figure 1 illustrates the typical reactor train and heat transfer fluid heat exchange network.
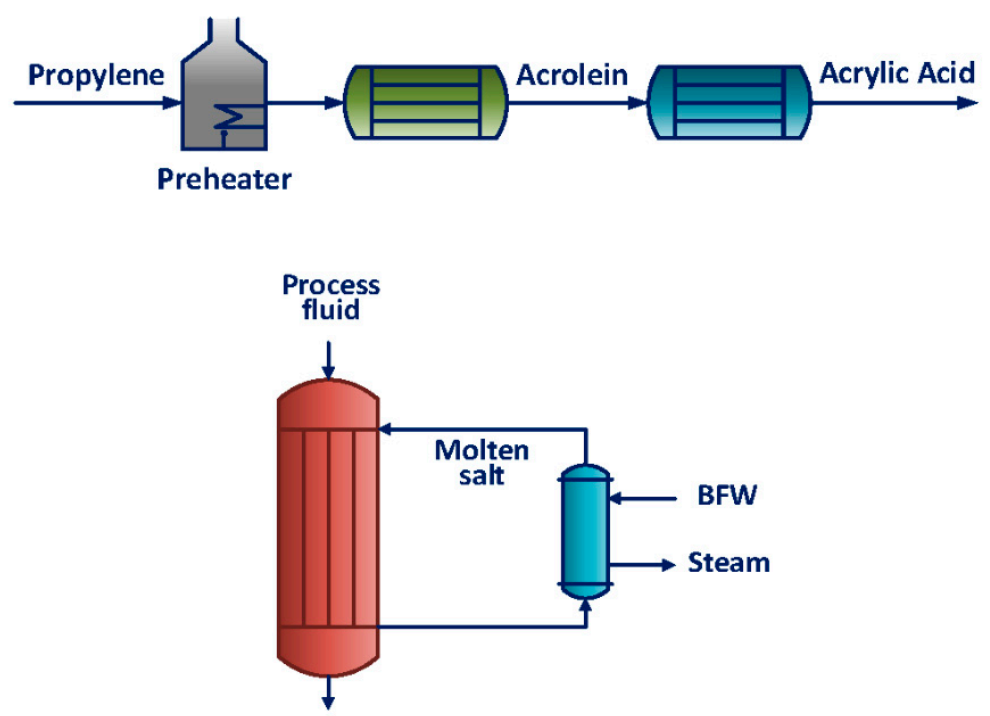

Figure 1. Typical reactor train and thermal fluid heat exchange network for acrylic acid production (BFW refers to boiler feed water).

The design, optimization and analysis of such a unit is a complicated task, since there are a large number of optimization variables to be considered. Proper representation of the reactor train in a process simulator is the first step towards heat integration, development of energy management strategies and overall understanding that could lead to intensification of the process [4]. Process simulation studies carried out on this process and reported in the literature have considered either adiabatic or fluidized bed reactor types with no in depth analysis of the more popular multitubular reactor configuration [2].

In this work, the rigorous design of a two-stage acrylic acid reactor train was undertaken and critical parameters identified for accurate representation of the unit in a process simulation platform. The study offers insight into the sensitivity of major performance criteria to the various operating parameters, many of which are unique to the multitubular reactor configuration.

\section{Method Development}

The reactor feed materials simulated in this work consists of a mixture of propylene with a purity of $94 \mathrm{~mol} \%$ (containing equimolar impurities of propane and ethane), low-pressure steam (432 K, 5 bar) and compressed air (10 bar). The feed streams are fed into two multitubular fixed bed reactors in series, R-101 and R-102. The two-step oxidation process presented in this work contains a coordination of catalysts, with differing microstructures and operating conditions for each reactor. The partial oxidation of propylene, Equation (1), occurs exothermally within R-101. The tubes are packed with a bismuth molybdate catalyst. The reactor feed composition is comprised of a ratio of 5:30:65 of propylene, steam and air. Low-pressure steam is added to the reactor feed to act as thermal ballast [5]. 
$\mathrm{R}-102$ operates within a lower temperature range and a vanadium molybdate catalyst. Molten salt was selected to be used as a coolant on the shell side to facilitate temperature control. The effluent from R-102 containing acrylic acid, unreacted propylene and associated byproducts, is then further processed and refined to the required grade of acrylic acid.

The multitubular fixed-bed reactor train was simulated on Aspen Plus ${ }^{\circledR}$ (AspenTech, Bedford, MA, USA) using the RPLUG (plug-flow reactor) model and the NRTL thermodynamic property method. The NRTL (non-random-two-liquid) thermodynamic property method was selected to simulate the physical properties of the reactant system, due to its ability to accurately predict highly nonideal chemical, polar or non-polar systems. The RPLUG model on Aspen Plus ${ }^{\circledR}$ (AspenTech, Bedford, MA, USA) employs ideal plug flow characteristics to the reacting systems. Therefore, radial velocity gradients were considered negligible. Interphase heat and mass transfer resistances and dispersion were also neglected. The RPLUG model required the following input parameters and reactor configuration choices for the rigorous design methodologies employed such as:

- Reaction kinetics

- Co-current or counter-current flow configurations

- Overall heat transfer coefficient

- Number of tubes, tube dimensions, reactor orientation

- Valid shell and tube side phases

- Catalyst bed voidage, particle density, particle diameter, particle shape factor

Reaction kinetics for the partial oxidation of propylene were extracted from Redlingshofer et al. [6], whilst Estenfelder and Lintz [7] reaction kinetics were used for the partial oxidation of acrolein to acrylic acid. The reaction kinetics used in this work were validated on Aspen Plus ${ }^{\circledR}$ (AspenTech, Bedford, MA, USA). A co-current flow configuration was selected. The overall heat transfer coefficient (per unit wall area) was interactively calculated using a macro-enabled excel spreadsheet which was coupled to the Aspen Plus ${ }^{\circledR}$ (AspenTech, Bedford, MA, USA) simulation platform for easy iteration during the development of the optimization methodology. Fouling factor resistances were extracted from literature. The overall heat transfer coefficient is given by Equation (7):

$$
\frac{1}{U_{i}}=\frac{1}{h_{i}}+\frac{1}{h_{i d}}+\frac{d_{i} \ln \left(\frac{d_{o}}{d_{i}}\right)}{2 k_{w}}+\frac{d_{i}}{d_{o}} \frac{1}{h_{o d}}+\frac{d_{i}}{d_{o}} \frac{1}{h_{o d}}+R
$$

where $U_{i}$ is the overall heat transfer coefficient based on the inside area of the tube, $h_{i}$ is the tube-side heat transfer coefficient, $h_{i d}$ is the tube-side dirt coefficient (fouling factor), $d_{o}$ is the tube outside diameter, $d_{i}$ is the tube inside diameter, $k_{w}$ is the thermal conductivity of the tube wall material, $h_{o d}$ is the shell-side dirt coefficient and $R$ is a heat transfer resistance parameter. The tube-side and shell-side heat transfer coefficients are functions of the tube bundle geometry, and fluid hydrodynamics on the tube-side and shell-side, respectively.

The wall heat transfer coefficient on the tube side was determined from a packed bed correlation to take into account the presence of the catalyst and is illustrated by Equations (8) to (11) [8]. Kern's shell side heat transfer coefficient correlation was used to approximate the heat transfer coefficient on the shell side [9].

$$
\begin{aligned}
\frac{h_{w} d_{p}}{k_{g}} & =0.16 \operatorname{Re}^{\prime} 0.93 \\
20 & <\operatorname{Re}^{\prime}<800 \\
0.03 & <d_{p} / d_{t}<0.2 \\
d_{p} & =6 V_{p} / S_{p}
\end{aligned}
$$

In Equations (8) to (12), $h_{w}$ is the wall heat transfer coefficient, $d_{p}$ is the diameter of the catalyst particles, $k_{g}$ and $k_{f}$ are the thermal conductivities of the process gas and thermal fluid, respectively, $d_{e}$ 
is the equivalent diameter of the of the flow area on the shell-side, Re and Pr are the fluid Reynolds and Prandtl numbers, and $\mu$ and $\mu_{w}$ are the fluid viscosities in the bulk and at the wall, respectively.

The reactor train and heat exchange network optimizations considered the following variables, design constraints and possible optimizations:

\section{Variables}

- Reactor length

- Number of tubes

- Heat transfer fluid flow rate

- Heat transfer fluid heat exchange circuit

- Catalyst physical properties

\section{Design Constraints/Possible Optimizations}

- Conversion of propylene above $95 \%$

- Complete conversion of acrolein

- Tube side pressure drop below $10 \%$

- Shell side pressure drop

- Temperature of propylene oxidation reactor between 633 and $703 \mathrm{~K}$ as per the selected reaction kinetics

- Temperature of acrolein oxidation reactor between 533 and $573 \mathrm{~K}$ as per the selected reaction kinetics

- Removal of hotspots and subsequent limitation of susceptibility to thermal runaway

- Minimization of heat transfer fluid usage

- Heat integration

Similar optimization methodologies were developed for reactors R-101 and R-102, with differences occurring due to the varying extents of the respective exothermic reactions. The Wegstein method is usually the most reliable method for tear stream convergence, such as with the RPLUG model in Aspen Plus ${ }^{\circledR}$ (AspenTech, Bedford, MA, USA). Interactions between variables are ignored therefore the Wegstein method results in oscillating solutions whenever variables are strongly coupled. Owing to the heavily coupled nature between the parameters, the sensitivity of each variable to the next was difficult to determine even when using combinations of optimizations, sensitivities and design spec/vary models in Aspen Plus ${ }^{\circledR}$ (AspenTech, Bedford, MA, USA). Consequently, algorithms were derived iteratively using the RPLUG model on Aspen Plus ${ }^{\circledR}$ (AspenTech, Bedford, MA, USA) in addition to manual (offline) iterations to ensure that the most optimum design choices for the reactors were made. The optimization methodology used aimed at minimizing the total capital expenditure and operating costs, i.e., minimizing reactor sizing and heat input, for the required design constraints.

The optimization procedure, illustrated by Figure 2, entailed iteratively adjusting the tube length to determine the most efficient length for the reactor. The reactor tube length affects the tube and shell side pressure drops since pressure drop correlations are directly proportional to tube length. In addition, the tube length determines the overall dimensions of the reactor since the tube length is inversely proportional to the number of tubes. The tube length was therefore iteratively varied whilst Aspen Plus ${ }^{\circledR}$ (AspenTech, Bedford, MA, USA) models were used to determine the minimum number of tubes required for the respective tube length, the thermal fluid inlet temperature and thermal fluid flow rate required. The minimum number of tubes was governed by the propylene and acrolein conversions specified, which was ultimately dependent on the reaction kinetics and heat transfer within the reactor. Both the reaction kinetics and heat transfer were constrained by the allowable temperature ranges per reactor. The allowable temperature ranges per reactor were controlled by varying the thermal fluid inlet temperature and flow rate. Preliminary base case reactor optimizations illustrated large tube side pressure drops that were not conforming to the allowable $10 \%$ design constraint for economical and practical industrial reactors. Hollow cylinder catalyst particles were selected for the simulation 
to improve the tube side pressure drop to within the design constraint. Following the optimization of the tube side pressure drop, preliminary analysis was conducted on the shell-side pressure drop. The shell-side pressure drop was increased to promote more efficient heat transfer on the shell side. The same methodology was applied to reactor R-102.

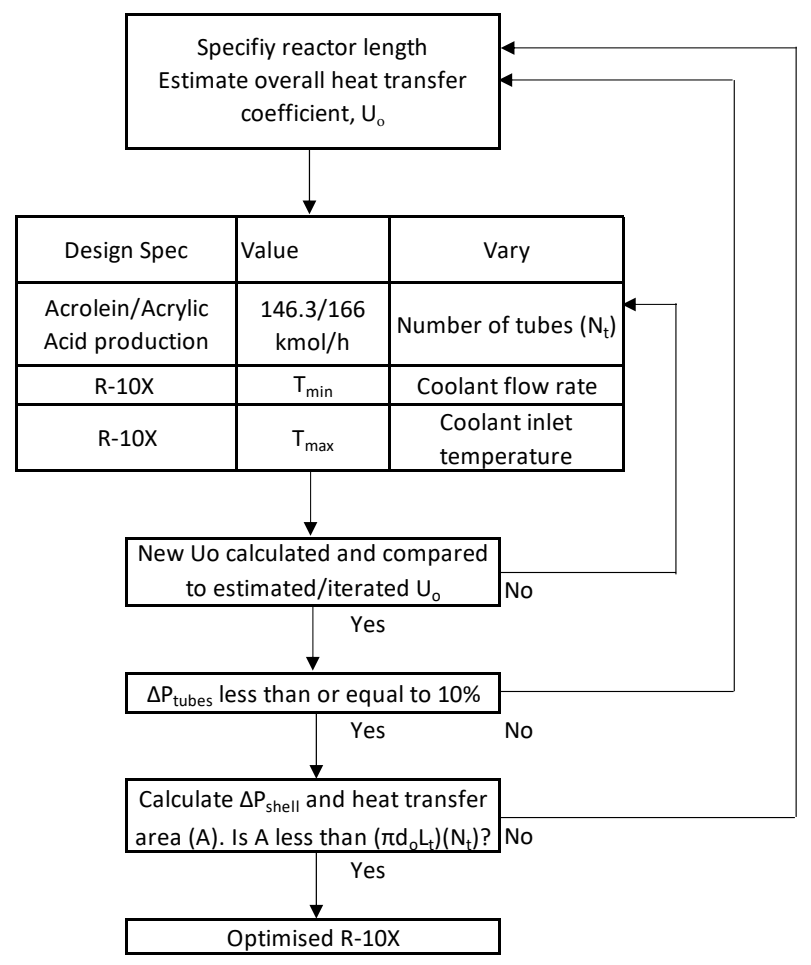

Figure 2. $\mathrm{R}-10 \mathrm{X}(\mathrm{X}=1$ or 2$)$ optimization algorithm.

The following subsections aim to discuss the differences in the optimization methodologies for R-101 and R-102.

Redlingshofer et al. [6] presented reaction kinetics that were valid in the temperature range from 633-703 K for the partial oxidation of propylene. Typically, a preheater would be used to ensure that the reactor feed temperature is within the required range for the reaction kinetics. The duty of heat exchange equipment required to increase the R-101 feed from a mixture temperature of $363 \mathrm{~K}$ to $633 \mathrm{~K}$ was calculated on Aspen Plus ${ }^{\circledR}$ (AspenTech, Bedford, MA, USA) as 6.19 MW. In typical Lurgi GmbH and Nippon Kayaku processes of acrylic acid, recovered heat from the exothermic reactions is used to generate steam. Instead of generating steam, in this work, an inert preheating zone was used in R-101, as illustrated by Figure 3, to use the heat absorbed by the molten salt circulating in R-101. This concept was derived from the production of phthalic anhydride.

Estenfelder and Lintz [7] presented reaction kinetics that were valid in the temperature range from 533-573 $\mathrm{K}$ for the partial oxidation of acrolein. When employing the method developed to optimize $\mathrm{R}-102$ as per the design constraints, the reactor temperature could not be maintained within the required temperature range due to the formation of a hotspot near the entrance of the reactor. Dilution of catalysts with inert material is a widely practiced means of mitigating hotspots in wall-cooled reactors, therefore alternate mass \% inert material were used to mitigate the hotspot, which is illustrated in Figure 3. As an initial estimate, 25 mass \% inert material was simulated in R-102 to determine the extent to which the reactor temperature would be controlled within the reactor. Increasing the mass \% of inert material however does increase the reactor dimensions as well as capital and operating costs.

An alternate method to remove the hotspot is therefore proposed in this work. With reference to the process of ethylene dehydrogenation, an air injection was used to lower the temperature of 
R-101 effluent and introduce sufficient inert (nitrogen) into the process fluid to successfully remove the hotspot [10].

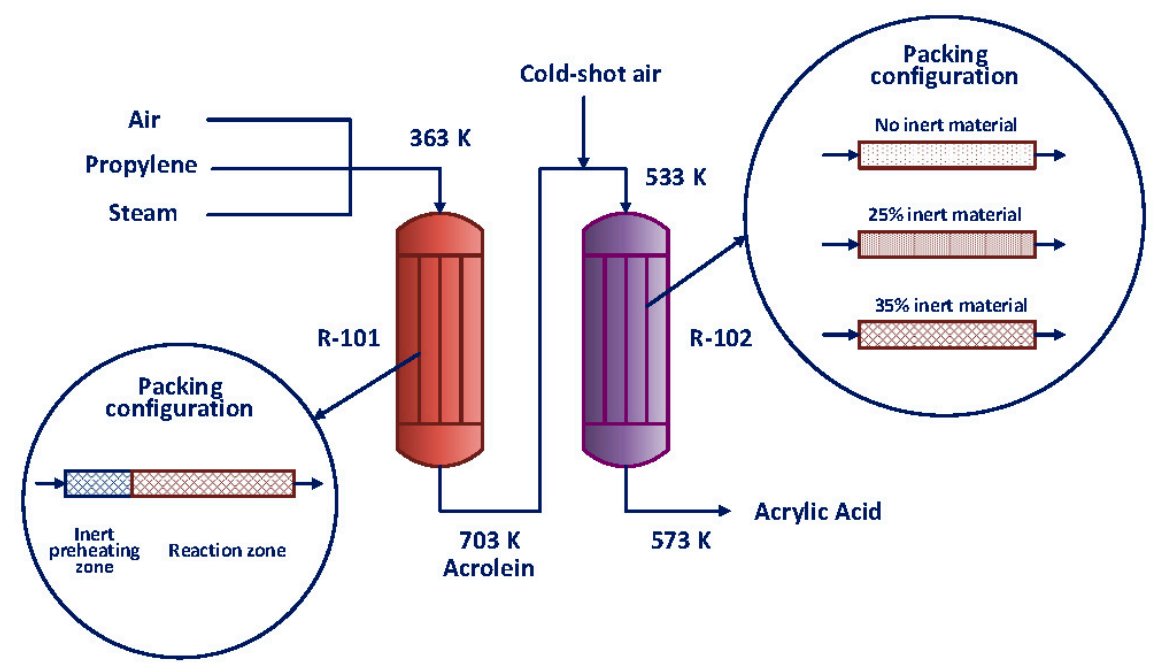

Figure 3. Studied process and catalyst packing configurations of multitubular fixed bed reactors R-101 and R-102.

\section{Results and Discussion}

\subsection{Reaction Method Selection}

Alternate paths are available for acrylic acid production. However, this work only explores the simulation and optimization of the partial oxidation of propylene to acrolein.

\subsection{Reactor Configuration}

Multitubular fixed bed reactors are commonly used for highly exothermic reactions to facilitate optimal heat removal. Tubular fixed bed reactors have an advantage that undesired consecutive reactions are suppressed to some extent.

The co-current flow arrangement was selected since parametric sensitivity behavior indicated that it would be the most attractive alternative from a steady state standpoint [11]. In the author's previous work on the partial oxidation of propylene to acrolein, the co-current configuration was selected as a method to effectively control the hotspot in comparison to a counter-current cooling circuit [3].

\subsection{Heat Transfer Fluid Selection}

The heat transfer fluid used on the shell side should be able to rapidly remove energy from the process without the requirement of impractically high flowrates. Molten salt heat transfer fluids were chosen due to their practicality for high temperature applications. Apart from being cost effective and nontoxic, molten salt has superior heat transport properties such as high heat capacities and high heat transfer coefficients such that the equipment size and surface areas for heat transfer can be held to a minimum. In addition, maintenance and power costs for circulating the molten salt are correspondingly low. Commercial $\mathrm{HTS}_{1}\left(40 \% \mathrm{KNO}_{3}\right.$ and $\left.60 \% \mathrm{NaNO}_{3}\right)$ and $\mathrm{HTS}_{2}\left(53 \% \mathrm{KNO}_{3}\right.$, $40 \% \mathrm{NaNO}_{2}$ and $7 \% \mathrm{NaNO}_{3}$ ) molten heat transfer salts were selected for their suitable operating temperature ranges, i.e., $422-853 \mathrm{~K}$ and $563-823 \mathrm{~K}$, respectively [12]. Molten salt physical properties, if modeled as a concentration of nitrate and nitrite salts in water, are grossly underestimated on Aspen Plus ${ }^{\circledR}$ (AspenTech, Bedford, MA, USA) and therefore do not accurately represent the heat transfer capability of molten salt. Therefore, a molten salt component was built into Aspen Plus ${ }^{\circledR}$ (AspenTech, Bedford, MA, USA) with the respective physical properties manually input. The physical properties were estimated as per correlations in literature [13]. 


\subsection{Catalyst Selection}

Catalyst selection incorporated several fundamentals presented by Grasselli [14] such as the need for lattice oxygen, metal oxygen bonds and using the appropriate host structure. Lattice oxygen is a versatile and more selective oxidizing agent than gaseous dioxygen. The basic idea is to use the metal oxygen as a reactant such that only desired products are favored during the oxidation of hydrocarbons. Following the need for lattice oxygen, the metal oxygen bond type needed was explored. If the bond is too strong, no reaction will occur. Conversely, undesired overoxidation may occur prevalently. The host structure should be pliable, able to contain lattice oxygen and be reduced without structural collapse. Taking these properties into consideration, bismuth molybdate, $\mathrm{Bi}\left(\mathrm{MoO}_{4}\right)_{3}$, and vanadium molybdate, $\mathrm{VMo}_{3} \mathrm{O}_{11}$, catalysts were selected for R-101 and R-102. These catalysts reported high selectivities towards acrolein and acrylic acid [15].

\subsection{Propylene Partial Oxidation Reaction Kinetics Validation}

Reaction kinetics for the partial oxidation of propylene over a bismuth molybdate catalyst were extracted from Redlingshofer et al. [6]. Acrolein oxidation to formaldehyde was considered negligible due to the low range of selectivities i.e. $0.73-0.78 \%$ [16]. The redox reaction mechanism for acrolein formation proceeds via two steps: reduction and oxidation reactions. Models such as the Mars-van-Krevelen and Langmuir-Hinshelwood rate expressions account for the crossover from oxidation to reduction reactions in a single expression. However, the power law reduction reaction was favored since the $\alpha$-bismuth molybdate catalyst selected, which has a high selectivity to acrolein of $88 \%-95 \%$, operates optimally in a temperature range of $623-723 \mathrm{~K}$ [6]. The kinetics were determined by statistical parameter estimation using experimental data from isothermal investigations and were valid over a temperature range of $633-703 \mathrm{~K}$. The kinetic parameters proved to be statistically significant as represented by their standard deviations, thereby validating the reaction kinetics presented. Further kinetic validations were conducted on Aspen Plus ${ }^{\circledR}$ (AspenTech, Bedford, MA, USA) to determine the feasibility of scaling up the lab-scale kinetics. The yield, conversion and selectivity profiles extracted from Redlingshofer et al. [16] correlated with the Aspen Plus ${ }^{\circledR}$ (AspenTech, Bedford, MA, USA) simulation results illustrated in Table 1, thereby validating the use of these kinetics in the design of an industrial-sized reactor as well as reinforcing the ease of scale-up with multitubular reactors.

Table 1. Validation of reactor kinetics for the partial oxidation of propylene by Redlingshofer et al. [16].

\begin{tabular}{ccc}
\hline Value & Conversion of Propylene (\%) & Selectivity to Acrolein (\%) \\
\hline Maximum & 61.4 & 89.7 \\
Minimum & 59.6 & 89.1 \\
Mean value & 60.3 & 89.5 \\
\hline
\end{tabular}

\subsection{Acrolein Partial Oxidation Reaction Kinetics Validation}

Estenfelder and Lintz [7] presented reaction kinetics for the partial oxidation of acrolein over vanadium molybdate oxide catalysts with varying compositions. The reactor network was treated as an isothermal plug flow reactor and kinetics were presented for $533 \mathrm{~K}$ and $573 \mathrm{~K}$. In order to approximate the kinetics for the temperature range from $533 \mathrm{~K}$ to $573 \mathrm{~K}$, linearization of the experimentally determined reaction rate constants was used. Kinetic validations were conducted on Aspen Plus ${ }^{\circledR}$ (AspenTech, Bedford, MA, USA) to determine the feasibility of scaling up the lab-scale kinetics. The yield and selectivities reported by Estenfelder and Lintz [7] correlated with the Aspen Plus ${ }^{\circledR}$ (AspenTech, Bedford, MA, USA) simulation results in Table 2, thereby validating the use of these kinetics in the design of an industrial-sized reactor as well as reinforcing the ease of scale-up with multitubular reactors. 
Table 2. Validation of reactor kinetics for the partial oxidation of acrolein, based on kinetic parameters extracted from Estenfelder and Lintz [7].

\begin{tabular}{ccc}
\hline Number of Tubes & ${ }^{\mathbf{1}}$ Selectivity of Acrylic Acid (\%) & $\mathbf{1}$ Yield of Acrylic Acid (\%) \\
\hline 500 & 96 & 97.92 \\
5000 & 96 & 97.96 \\
10,000 & 96 & 98.03 \\
15,000 & 96 & 97.98 \\
20,000 & 96 & 97.91 \\
\hline
\end{tabular}

${ }^{1}$ Estenfelder and Lintz [7] reported a selectivity to acrylic acid of $98 \%$ and a yield of $95 \%$.

\subsection{Assumptions and Simulation}

Rigorous design of multitubular reactors can be effectively carried out in the Aspen Plus ${ }^{\circledR}$ (AspenTech, Bedford, MA, USA) simulation platform, provided that mass transfer resistances are either designed-out or accounted for in the reaction rate [17]. Design heuristics, in Table 3, from the indicated literature sources were used to develop the optimized reactor configuration in this work. Heat and mass transfer approximations and calculations were critically evaluated in the reactor.

Table 3. General multitubular rector design heuristics.

\begin{tabular}{cc}
\hline Recommended Ranges/Estimates & Reference \\
\hline Shell side velocity ranges: & {$[9]$} \\
$0.3-1 \mathrm{~m} / \mathrm{s}$ & {$[18]$} \\
$0.9-1.5 \mathrm{~m} / \mathrm{s}$ & \\
$0.25-0.65 \mathrm{~m} / \mathrm{s}$ & {$[19]$} \\
Catalyst particle diameter should be $10 \%$ of tube diameter to prevent channeling. & [9] \\
Liquids with viscosities more than $1 \mathrm{mPa} \cdot \mathrm{s}$ are restricted to a maximum shell-side \\
pressure drop within the range 50-70 kPa.
\end{tabular}

The RPLUG model on Aspen Plus ${ }^{\circledR}$ (AspenTech, Bedford, MA, USA) assumes ideal plug flow. Axial and radial dispersion was neglected since the tube length to particle diameter was large. Since both heat and mass transfer coefficients increase with increasing mass velocities, in most industrial reactors with large throughputs at high pressures, it is practical to avoid significant interphase gradients.

Convergence on the optimization model could not be achieved by varying all critical parameters together due to their heavily coupled nature therefore, the iterative methods in the algorithms illustrated by Figure 2 was used to best approximate a convergence sequence.

Sensitivities were conducted on the thermal fluid flow rate and inlet temperature using a base case reactor to determine which variable controlled the maximum and minimum temperatures within the reactor. For R-101, the heat transfer fluid flow rate affected the minimum temperature the most whilst the maximum temperature was affected by the heat transfer fluid inlet temperature the most, as illustrated by Table 4 . The same methodology was applied to reactor R-102. 
Table 4. R-101 sensitivity results to determine relationship between parameters.

\begin{tabular}{cccc}
\hline $\begin{array}{c}\text { Acrolein Production } \\
\text { (kmol/h) }\end{array}$ & $\begin{array}{c}\mathbf{1} \text { Temperature } \\
\text { Range (K) }\end{array}$ & $\begin{array}{c}\text { Temperature of Heat } \\
\text { Transfer Fluid (K) }\end{array}$ & $\begin{array}{c}\text { Flow Rate of Heat } \\
\text { Transfer Fluid (kmol/s) }\end{array}$ \\
\hline 172 & $613-693$ & 578 & 3 \\
169 & $623-703$ & 588 & 3 \\
162 & $624-731$ & 588 & 2.5 \\
158 & $631-747$ & 598 & 2.5 \\
155 & $632-767$ & 598 & 2.25 \\
162 & $633-724$ & 600.5 & 3 \\
166 & $633-705$ & 600.5 & 3.5 \\
169 & $633-697$ & 600.5 & 3.75 \\
\hline
\end{tabular}

${ }^{1}$ Required temperature range for R-101 was 633 to $703 \mathrm{~K}$.

The overall heat transfer coefficient in exothermic reactions can independently determine the size of a reactor unit and is therefore of pivotal importance. All heat transfer resistances were taken into consideration when determining the overall heat transfer coefficient and then iterated in the optimization methodologies used.

The feasibility of the packed bed design is substantially dependent on the catalyst structure and packing matrix employed. The catalyst is also required to be resistant to crushing and abrasion. Spherical catalyst particles are commonly used for propylene partial oxidation in industry. However, owing to the large tube-side pressure drop, which exponentially surpassed the general design heuristic of $10 \%$, the catalyst geometry was revisited and hollow cylinder catalyst pellets were selected [19]. The use of hollow cylinder catalyst pellets enhances conversion levels in reactors due to the better utilization of the catalytic material, with the most notable feature being the absence of the pellet core, which lowers internal transport resistances and the reactor pressure drop [20]. Greater catalyst surface areas result in smaller reactor volumes, which is arguably the ultimate design feasibility decision. Therefore, hollow cylinder catalysts were selected and ensured that the tube side pressure drop was within $10 \%$ [21]. Following the control of the tube side pressure drop, analysis was conducted on the shell-side pressure drop. Low shell-side pressure drops are indicative of low turbulence in the shell. Heat transfer coefficients are directly proportional to Reynolds number, which is an indication of the degree of turbulence. A high heat transfer coefficient would require a smaller heat transfer surface area, thereby reducing the size of the reactor, by increasing the overall heat transfer coefficient. As a result, higher turbulence on the shell side was required. The shell-side pressure drop was therefore increased by varying the reactor tube length until the tube-side pressure drop constraint was met. These results are illustrated in Table 5 for R-101. A similar optimization procedure was conducted for R-102.

Heat integration was employed within R-101 to negate the additional capital and operating costs associated with a waste heat exchanger network. Reactor R-101 is essentially modeled and simulated as two series reactors with an inert preheating zone and a reacting zone, as illustrated by Figure 3 . The preheating zone was used as part of energy optimization since the temperature of molten salt needed to heat the feed to $633 \mathrm{~K}$ was close to the exiting molten salt temperature. The resultant temperature and composition profiles in R-101 are illustrated by Figure 4. 
Table 5. R-101 optimization results.

\begin{tabular}{ccc}
\hline Length $(\mathrm{m})$ & Parameters & Value \\
\hline & Number of tubes: & 11,717 \\
& Overall heat transfer coefficient $\left(\mathrm{W} / \mathrm{m}^{2} \mathrm{~K}\right)$ & 409 \\
Coolant mole flow rate $(\mathrm{kmol} / \mathrm{s}):$ & 3.75 \\
Coolant inlet temperature $(\mathrm{K}):$ & 652 \\
Tube-side pressure drop $(\mathrm{Pa}):$ & 20,161 \\
Shell-side pressure drop $(\mathrm{Pa}):$ & 9938 \\
& Heat transfer surface area $\left(\mathrm{m}^{2}\right)$ & 1844 \\
& Number of tubes: & 9952 \\
& Overall heat transfer coefficient $\left(\mathrm{W} / \mathrm{m}^{2} \mathrm{~K}\right)$ & 449 \\
& Coolant mole flow rate $(\mathrm{kmol} / \mathrm{s}):$ & 3.75 \\
& Coolant inlet temperature $(\mathrm{K}):$ & 624 \\
& Tube-side pressure drop $(\mathrm{Pa}):$ & 32,908 \\
Shell-side pressure drop $(\mathrm{Pa}):$ & 14,803 \\
& Heat transfer surface area $\left(\mathrm{m}^{2}\right)$ & 1827 \\
& Number of tubes: & 9028 \\
& Coolant mole flow rate $(\mathrm{kmol} / \mathrm{s}):$ & 471 \\
& Coolant inlet temperature $(\mathrm{K}):$ & 3.75 \\
& Tube-side pressure drop $(\mathrm{Pa}):$ & 623 \\
& Shell-side pressure drop $(\mathrm{Pa}):$ & 45,185 \\
& Heat transfer surface area $\left(\mathrm{m}^{2}\right)$ & 19,439 \\
& & 1805 \\
\hline
\end{tabular}

(A)

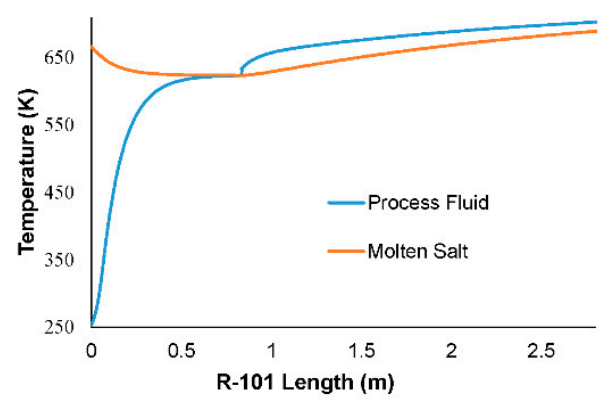

(B)

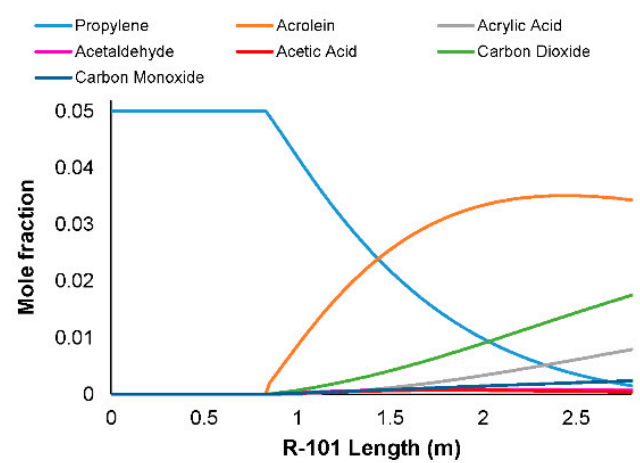

Figure 4. R-101 temperature and molar composition profiles: (a) process fluid and molten salt temperature profiles in R-101 for inert preheating and reacting zones; (b) molar composition profile in R-101 of major components.

The optimization algorithms for R-101 and R-102 are similar, with differences occurring due to the varying extents of the respective exothermic reactions. Temperature ranges and hotspot formation were more difficult to control in R-102 as compared to R-101 hence rigorous design changes to R-102 were made. As an initial estimate, 25 mass \% inert material was assumed to be used in R-102 to determine the extent to which the reactor temperature would be controlled. In addition, the hotspot was required to be mitigated since the reaction is prone to rapid runaway with minor coolant variations. Figure 5 illustrates the results of sensitivities conducted on varying quantities of inert material ( 0 to 45 mass \%) in an attempt to control the reaction temperature range as well as prevent the formation of the hotspot. The temperature profile along the reactor is typical of that for a highly exothermic and rapid reaction. When the temperature of the reaction mixture reaches a satisfactory value with fresh catalyst, the reaction takes off and a hotspot begins to develop. The reaction temperature rapidly exceeds the salt temperature. The reaction rate increases exponentially and the heat removal rate increases only linearly as the reaction mixture temperature exceeds the temperature of the molten salt. The temperature begins to decline as the reaction rate declines with increasing conversion. 
(A)

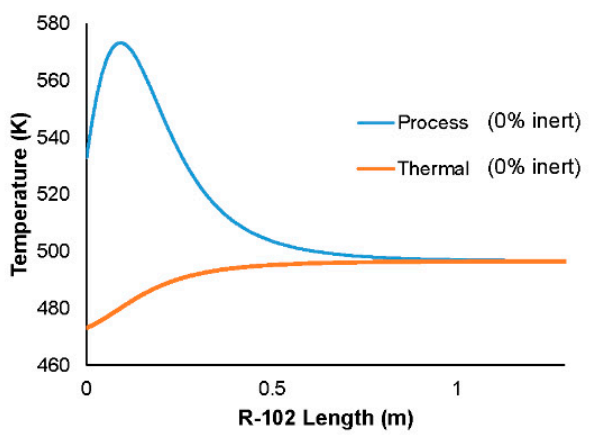

(C)

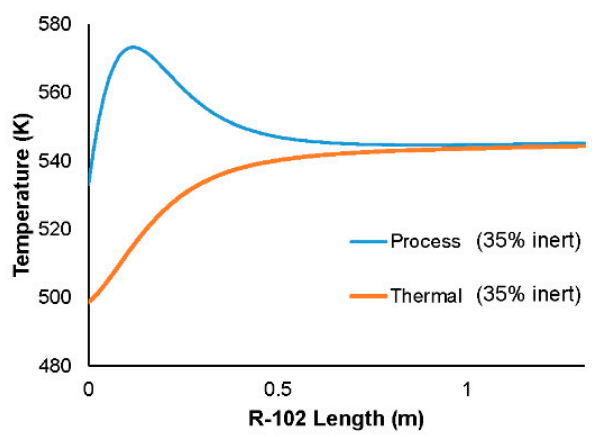

(B)

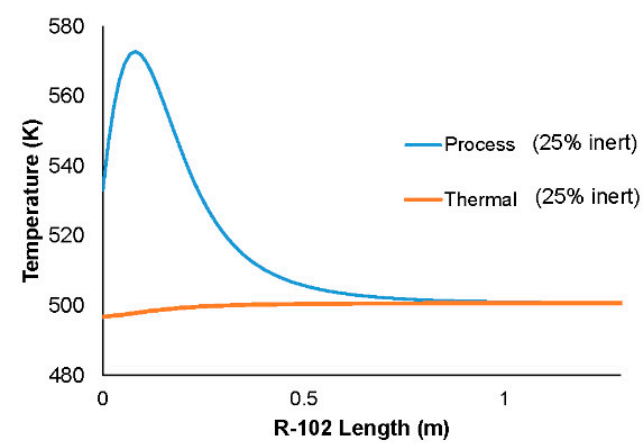

(D)

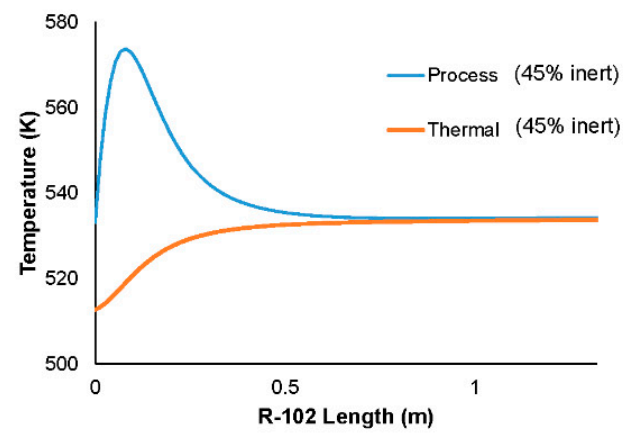

Figure 5. R-102 temperature profiles for varying inert compositions (- Process fluid temperature; - Molten salt temperature): (a) R-102 temperature profile for 0 mass \% inert material; (b) R-102 temperature profile for 25 mass \% inert material; (c) R-102 temperature profile for 35 mass \% inert material; (d) R-102 temperature profile for 45 mass \% inert material.

By incorporating inert material into the catalyst bed, the reaction and heat generation rate per unit volume is decreased, and it was postulated that this may be able to eliminate the hotspot. The actual shape and limits of the temperature profiles are dependent on the feed temperatures for the process fluid and thermal fluid, the driving force for heat transfer and the net generation of heat within the reaction zone [22]. As can be seen in Figure 5, all inert packing configurations exhibited hotspot behavior, thus the incorporation of inert material into the bed, even up to $45 \%$, did not have the necessary effect on the temperature moderation and hence selectivity. In the case of 35\% inert, the system exhibited a high final temperature, with a flatter and more sustained overtemperature in the response. Since the simulations were carried out with constraints on the overall conversion, the reduced rate at the start of the bed required a higher temperature towards the end of the bed to meet the necessary conversion value. Such behavior was not observed for the $45 \%$ inert system. Here the driving force for heat transfer was low and once the reaction was initiated, a rapid increase in temperature and conversion was observed, as in the case of $0 \%$ and $25 \%$ inert material.

As illustrated, since the reaction could still not be optimally controlled, literature was consulted to determine other methods of optimal temperature control in similar exothermic, runaway reactions. A multitubular reactor process for the oxidative dehydrogenation of ethylene was studied due to the similarities between the processes [10]. The reactor had a runaway temperature problem which was overcome by the use of distributed air injection schemes. The injection of cold feed is often used for the control of the reaction exotherm [23]. The ratio of oxygen to nitrogen in air essentially controls the reaction rate due to the inert nitrogen, hence allowing a wider range of operation. A similar methodology was applied to R-102. A cold injection of air was used to collectively cool R-101 effluent to the required temperature of $533 \mathrm{~K}$ whilst ensuring that the feed stream contained sufficient inert gases to control the reaction rate in R-102 and hence remove the formation of the hotspot. These results are illustrated by Figure 6. 
(A)

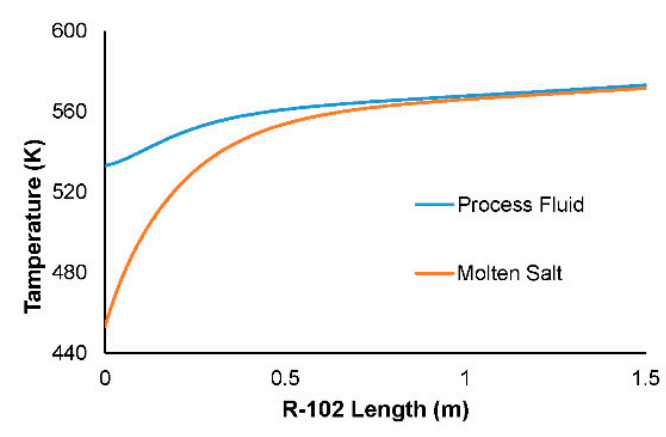

(B)

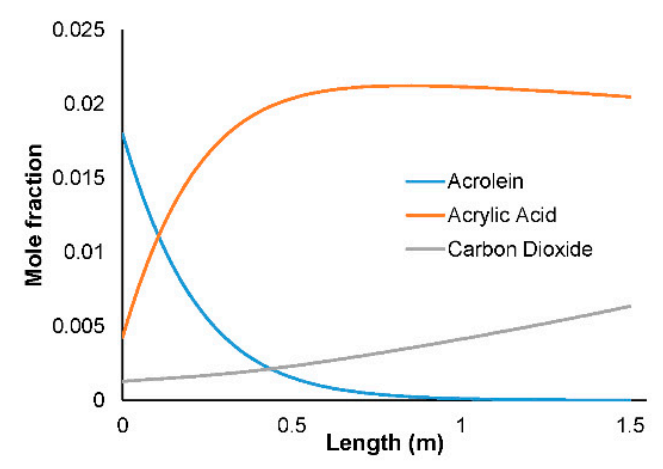

Figure 6. R-102 temperature and molar composition profiles: (a) process fluid and molten salt temperature profile in R-102; (b) molar composition profile in R-102 of major components.

\section{Energy Analysis}

In an attempt to quantify the energy savings from each of the design modifications proposed, we undertook calculations of the heat loads and associated pumping requirements for the molten salt heat transfer fluid systems for each reactor. For reactor R-101 (propylene oxidation reactor), the main design modification is the use of an inert preheating zone for preheating the feed. This is in lieu of a traditional fired preheater. The energy for preheating is obtained from the circulating thermal fluid and hence a higher flowrate of thermal fluid would be required when compared to the base case (traditional preheater and thermal fluid required only for cooling of the exothermic process fluid). The total heat duty required for pre-heating the propylene, air and steam mixture is $6190 \mathrm{~kW}$, which translates into an increase of $1.64 \mathrm{kmol} / \mathrm{s}$ in the molten salt flowrate. Under the specified operating conditions of the unit, this equates to an additional $283 \mathrm{~m}^{3} / \mathrm{h}$ of molten salt. With a standard molten salt pump operating at $75 \%$ efficiency, this requires $3.5 \mathrm{~kW}$ additional pumping power. Because the inlet and outlet temperatures of the thermal fluid are approximately the same, there would be practically no need for a large heat rejection system, e.g. using a waste heat boiler, and hence a saving on capital and maintenance cost. The overall energy saving for R-101 would then be associated with the energy requirements for preheating the feed. At $90 \%$ efficiency for a traditional fired heater, this equates to $6878 \mathrm{~kW}$, which is far greater than the associated increase in pumping power for the molten salt circuit.

In R-102 (the acrolein oxidation reactor), the main design modification is the cold injection of air (which is implemented without the introduction of inert solid material into the catalyst bed). We have compared the energy requirements of this process configuration to that of the base case (no injection of cold air nor the use of inert material), in terms of the total flowrate of molten salt and pumping requirements for the molten salt circuit. With reference to Figure 5a (base case) and Figure 6a (cold air injection), the base case is characterized by a rapid increase in process temperature due to the exothermic reaction, with practically all conversion occurring within the first quarter of the reactor. The total molten salt flowrate required for the base case is $10.13 \mathrm{kmol} / \mathrm{s}$, or $1658 \mathrm{~m}^{3} / \mathrm{h}$, which equates to a pumping power of $23 \mathrm{~kW}$. The total molten salt flowrate required for the modified configuration (cold air injection) is $7.8 \mathrm{kmol} / \mathrm{s}$, or $1278 \mathrm{~m}^{3} / \mathrm{h}$, equating to a pumping power of $17.6 \mathrm{~kW}$. The saving in terms of pumping power is therefore $5.4 \mathrm{~kW}$, with the additional benefit of increased selectivity and overall yield of acrylic acid.

\section{Future Work}

Future work to be investigated includes:

- Rigorous thermodynamic model selection for the reactant and product components via experimental data regression.

- $\quad$ The Aspen Plus ${ }^{\circledR}$ (AspenTech, Bedford, MA, USA) simulation model operation in this work is at steady state. A dynamic simulation can be developed to understand the impact of common 
operational changes, upsets and abnormal conditions; and thereafter develop a control procedure for the intensified process presented.

- The extent of the transferability of the optimized gas phase oxidation process in this work, to other highly exothermic, gas phase reactions.

- The optimized process in this work assumed negligible interphase heat and mass transfer resistances, axial dispersion and radial gradients. Future work can delve into the impacts of these non-idealities on the optimized process.

- Future work can explore the impact of catalyst deactivation on the optimized process, and the available levers to enable the optimized process until the catalyst end of run conditions.

\section{Conclusions}

The design of a multitubular fixed bed reactor train for the production of acrylic acid involves simultaneous consideration of various influencing parameters, including shell side heat transfer, shell side pressure drop, tube-side hotspot formation, tube side pressure drop, catalyst interfacial gradients and selection of inlet conditions. For both the propylene oxidation reactor (R-101) and acrolein oxidation reactor (R-102), the heat transfer fluid flow rate affected the minimum temperature the most whilst the maximum temperature was affected by the heat transfer fluid inlet temperature the most. Some of the energy carried in the molten salt recycle was utilized to preheat the feed to reactor R-101 by including an inert packed zone of approximately $0.8 \mathrm{~m}$ at the front of the reactor. This eliminated the need for a separate preheating exchanger before the reactor. Allowing for some reduction of the molten salt temperature at the front end of reactor R-101 also limited the overall temperature rise in this unit for both the process and thermal fluid. Dilution of catalyst was investigated as a means of regulating the bed temperature in the acrolein oxidation reactor R-102. However, employing solid inert material up to $45 \%$ did not significantly reduce the temperature rise or peak temperature in the reactor. An alternative strategy of cold air injection at the inlet of the reactor was successful in mitigating hotspot formation and allowing for a gradual increase in process side temperature, albeit with a higher final temperature than in the case of catalyst bed dilution. The accurate representation of the process performance on the Aspen Plus ${ }^{\circledR}$ (AspenTech, Bedford, MA, USA) platform allowed for probing of alternative energy utilization strategies. Owing to the elimination of the fired preheater from the front end of the process, the reduction in energy was almost $7 \mathrm{MW}$. The use of the cold air injection in the second reactor reduced thermal fluid pumping power requirements by over $5 \mathrm{~kW}$.

Author Contributions: Conceptualization, D.L.; methodology, K.C.P.; software, K.C.P.; validation, K.C.P. and D.L.; formal analysis, K.C.P.; investigation, K.C.P.; resources, K.C.P.; data curation, K.C.P.; writing-original draft preparation, K.C.P. and D.L.; writing—review and editing, D.L.; visualization, K.C.P.; supervision, D.L.; project administration, D.L.; funding acquisition, D.L. All authors have read and agreed to the published version of the manuscript.

Funding: This work is based on research supported by the National Research Foundation of South Africa, unique grant number 120019. The authors also acknowledge financial support from ESKOM.

Conflicts of Interest: The authors declare no conflict of interest. The funders had no role in the design of the study; in the collection, analyses, or interpretation of data; in the writing of the manuscript, or in the decision to publish the results.

\section{References}

1. Turton, R.; Bailie, R.C.; Whiting, W.B.; Shaelwitz, J.A. Analysis, Synthesis and Design of Chemical Processes, 3rd ed.; Prentice Hall: Upper Saddle River, NJ, USA, 2009; p. B.9.

2. Sou, M.; Zhang, H.; Ye, Q.; Dai, X.; Yu, H.; Li, R. Design and control of an improved acrylic acid process. Chem. Eng. Res. Des. 2015, 104, 346-356.

3. Jiang, B.; Hao, L.; Zhang, L.; Sun, Y.; Xiao, X. Numerical investigation of flow and heat transfer in a novel configuration multi-tubular fixed bed reactor for propylene to acrolein process. Heat Mass Trans. 2015, 51, 67-84. [CrossRef] 
4. Tripodi, A.; Compagnoni, M.; Martinazzo, R.; Ramis, G.; Rossetti, I. Process simulation for the design and scale up of heterogeneous catalytic process: Kinetic modelling issues. Catalysts 2017, 7, 159. [CrossRef]

5. Luyben, W. Economic Trade-offs in acrylic acid production. Comp. Chem. Eng. 2017, 93, 118-127. [CrossRef]

6. Redlingshofer, H.; Fischer, A.; Weckbecker, K.H.; Emig, G. Kinetic modelling of the heterogeneously catalyzed oxidation of propene to acrolein in a catalytic wall reactor. Ind. Eng. Chem. Res. 2003, 42, 5482-5488. [CrossRef]

7. Estenfelder, M.; Lintz, H.G. Simultaneous determination of reaction kinetics and oxygen activity in single-phase oxidic catalysts and their mixture during partial oxidations. J Catal. 2002, 209, 177-185. [CrossRef]

8. Stankiewicz, A. Advances in modelling and design of multitubular fixed-bed reactors. Chem. Eng. Tech. 1989, 12, 113-130. [CrossRef]

9. Sinnott, R.K. Chemical Engineering Design; Butterworth-Heinemann: Oxford, UK, 2005.

10. Fattahi, M.; Kazemeini, M.; Khorasheh, F.; Darvishi, A.; Rashidi, A.M. Fixed-bed multi-tubular reactors for oxidative dehydrogenation in ethylene process. Chem. Eng. Tech. 2013, 36, 1691-1700. [CrossRef]

11. Borio, D.O.; Gatica, J.E.; Porras, J.A. Wall cooled fixed bed reactors: Parametric sensitivity as a design criterion. AIChE J. 1989, 35, 287-292. [CrossRef]

12. Kawakami, M.; Suzuki, K.; Yokoyama, S.; Takenaka, T. Heat Capacity Measurement of Molten $\mathrm{NaNO}_{3}-\mathrm{NaNO}_{2}-\mathrm{KNO}_{3}$ by Drop Calorimetry. In Proceedings of the VII International Conference on Molten Slags Fluxes and Salts, Cape Town, South Africa, 25-28 January 2004; The South African Institute of Mining and Metallurgy: Johannesburg, South Africa, 2004; pp. 201-208.

13. Serrano-Lopez, R.; Fradera, J.; Cuesta-Lopez, S. Molten salts database for energy applications. Chem. Eng. Process. 2013, 73, 87-102. [CrossRef]

14. Grasselli, R.K. Fundamental principles of selective heterogeneous oxidation catalysis. Top. Catal. 2002, 2, 1-3. [CrossRef]

15. Snyder, T.P.; Hill, C.G. The mechanism for the partial oxidation of propylene over bismuth molybdate catalysts. Catal. Rev. 1989, 31, 43-95. [CrossRef]

16. Redingshofer, H.; Krocher, O.; Bock, W.; Huthmacher, K.; Emig, G. Catalytic wall reactor as a tool for isothermal investigations in the heterogeneously catalyzed oxidation of propene to acrolein. Ind. Eng. Chem. Res. 2002, 41, 1445-1453. [CrossRef]

17. Zhu, J.; Araya, S.S.; Cui, X.; Sahlin, S.L.; Kaer, S.K. Modeling and design of a multi-tubular packed-bed reactor for methanol steam reforming over $\mathrm{Cu} / \mathrm{ZnO} / \mathrm{Al}_{2} \mathrm{O}_{3}$ catalyst. Energies 2020, 13, 610. [CrossRef]

18. Shah, R.K.; Sekulic, D.P. Fundamentals of Heat Exchanger Design; John Wiley and Sons: New York, NY, USA, 2003.

19. Rase, H.F. Fixed Bed Reactor Design and Diagnostics: Gas-Phase Reactions; Butterworths: Boston, MA, USA, 1990.

20. Asif, M. Conversion enhancement of fixed-bed reactors using two-dimensional hollow cylindrical catalyst pellet. Int. J. Chem. React. Eng. 2013, 11, 159-168. [CrossRef]

21. Afandizadeh, S.; Foumeny, E.A. Design of packed bed reactors: Guides to catalyst shape, size and loading selection. Appl. Thermal Eng. 2001, 21, 669-682. [CrossRef]

22. Schüler, C.; Wolf, M.; Hinrichsen, O. Contactless temperature measurements under static and dynamic reaction conditions in a single-pass fixed bed reactor for $\mathrm{CO}_{2}$ methanation. J. CO2 Util. 2018, 25, 158-169. [CrossRef]

23. Marlin, D.S.; Sarron, E.; Sigurbjörnsson, Ó. Process Advantages of Direct $\mathrm{CO}_{2}$ to Methanol Synthesis. Front. Chem. 2018, 6, 446. [CrossRef] [PubMed]

(C) 2020 by the authors. Licensee MDPI, Basel, Switzerland. This article is an open access article distributed under the terms and conditions of the Creative Commons Attribution (CC BY) license (http://creativecommons.org/licenses/by/4.0/). 